\title{
DBD PLAZMA AKTÜATÖR SÜRÜM FREKANSININ UÇAK KANADI ETRAFINDAKİ AKIŞIN KONTROLÜNE ETKISIININ İNCELENMESİ
}

\author{
${ }^{1}$ Hürrem AKBIYIK ${ }^{(D)},{ }^{2}$ Hakan YAVUZ \\ 1,2Çukurova Üniversitesi, Mühendislik Fakültesi, Makina Mühendisliği Bölümü, Adana, TÜRKIYYE \\ ${ }^{1}$ hakbiyik@cu.edu.tr, ${ }^{2}$ hyavuz@cu.edu.tr
}

(Geliş/Received: 31.12.2019; Kabul/Accepted in Revised Form: 12.02.2020)

\begin{abstract}
ÖZ: Yapılan çalışma ile NACA0015 uçak kanadı etrafındaki akışın kontrolünde plazma aktuatörlerin $\mathrm{Re}=48000$ değerinde sürüm frekansı ve voltajındaki değişmenin kaldırma kuvvetine etkisi incelenmiştir. Bu kapsamda yapılan çalışmalar ile plazmanın oluşturulmasında etkili olan parametrelerin direkt olarak aerodinamik performansa etkisi değerlendirilmiştir. Yapılan incelemede plazma aktüatörler uçak kanadının ön kısmına $(\mathrm{x} / \mathrm{C}=0.1)$ yerleştirilmiştir. Deneysel çalışmalar kapsamında ise frekans değişimi ile yüksek hücum açılarındaki ayrılan akışın incelemesi yapılmıştır. Literatürdeki çalışmalar göz önüne alındığında çalışmaların büyük çoğunluğunun stol açısı ve post stol açıları için yapıldığı görülmektedir. Yapılan deneysel çalışmalarda, belirli bir hücum açısı aralığı için frekansın ve voltajın etkileri incelenmektedir. Yapılan deneysel çalışmalar sonucunda elde edilen bulgulardan özellikle plazma aktüatörlerin uygulama voltajının kaldırma katsayısına doğrudan oransal etkisi tespit edilmiştir. Diğer taraftan, sürüm frekansının ise belirgin bir ilişkisi tespit edilememiştir. Bu ilişki daha çok doğrusal olmayan bir yapı şeklinde görünmektedir. Bu durum, özellikle çalışmanın bulgular kısmında detaylı olarak incelenmiştir.
\end{abstract}

Anahtar Kelimeler: Plazma aktüatör, Aktif akış kontrolü, Aerodinamik performans, Kaldırma kuvveti katsayısı, Plazma sürüm frekansı

\section{Investigation of the Effect of DBD Plasma Actuator Excitation Frequency on Flow Control Around an Aircraft Wing}

\begin{abstract}
In this study, the effect of variation of plasma excitation frequency and applied voltage variation on lift coefficient of NACA0015 airfoil is investigated at $R e=48000$. In this context, the effects of the parameters direct effecting the plasma generation on the aerodynamic performance of the airfoil are assessed. In this study, plasma actuators are located at near leading edge $(\mathrm{x} / \mathrm{C}=0.1)$ position. Within the scope of the experimental studies, the separated flow is studied for the excitation frequency at high attack angles. When the studies in the literature are taken into consideration, it is seen that the majority of the studies are performed for stall angle and post stall angles. In experimental studies, the effects of frequency and voltage are examined for a certain angle of attack angle. As a result of the experimental studies, the direct proportional effect of the application voltage of the plasma actuators on the lift coefficient was determined. On the other hand, no significant correlation was found between excitation frequency. This relationship appears to be more of a non-linear structure. This has been examined in detail in the findings section of the study.
\end{abstract}

Key Words: Plasma actuator, Active flow control, Aerodynamic performance, Lift coefficient, Plasma excitation frequency 


\section{GİRİŞ (INTRODUCTION)}

Son yıllarda, DBD plazma aktüatörler akışın kontrolünde önemli bir aktif akış kontrol elemanı olarak kullanılma başlanmıştır. Plazma aktüatörlerin tamamen elektronik yapıda olmaları, istenildiğinde devreye kolay bir şekilde alınmaları ya da devre dışı bırakılabilmeleri, hareketli parçalara sahip olmamaları dolayısı ile geometriyi değiştirmemeleri ve hızlı cevap süreleri sayesinde sisteme hızı müdahale imkânı vermelerinden dolayı bu konu üzerine yapılan çalışmalar giderek artmaktadır.

Bir DBD plazma aktüatörün yapısı birisi hava ile temas eden diğeri gömülü iki elektrottan ve bunların arasına yerleştirilmiş bir dielektrik malzemeden oluşmaktadır. Bu elektrotlara AC voltaj uygulanması neticesinde aktüatörler üzerinde iyonize gaz oluşmaktadır. Bu alanda AC voltaj ile birlikte DC voltaj esaslı plazma aktüatörlerde kullanılmaktadır. Ancak, AC uygulamaların DC uygulamalara kıyasla elektrot korozyonuna daha az maruz bırakması ve iyonize gaz oluşumunda daha güç gerektirmesi avantajlarından dolayı aerodinamik akış kontrolünde daha çok tercih edilmektedir (Corke ve diğ., 2010). Aktif akış kontrolünde kullanılan bu aktüatörler sayesinde üretilen iyonize gazın (plazma) hızı akışın kontrolünde önemli bir rol oynamaktadır. Yani, akış kontrolünün etkinliği aktüatör performansı ile doğrudan ilişkilidir. Bu noktada, aktüatörün geometrisi, sürüm voltajı tipi, dielektrik malzemenin katman kalınlığı ve çeşidi, aktüatör elektrotları arası boşluk ve sürüm frekansı önemli rol oynamaktadır. Debien ve diğ. (2012) yaptıkları çalışmada bir plazma aktüatör yardımıyla üretilen itki kuvvetini yani plazmanın etkisini yaptıkları deneysel çalışmada göstermişlerdir. Deneysel çalışmalarında, birinci durumda frekansı sabit tutup uygulama voltajını 12 ile $22 \mathrm{kV}$ aralığında diğer durumda ise uygulama voltajını sabit tutup sürüm frekansını 0.5 ile $2 \mathrm{kHz}$ aralığında değiştirip üretilen itki kuvvetini incelemişlerdir. Voltaj ve frekansın değişiminin itki kuvvetine doğrudan etki ettiğini ve bu değerlerdeki artışın plazmanın etkinliğini de arttırdığını belirtmişlerdir (Debien ve diğ., 2012). Orlov (2006) yaptığı çalışmada, plazma yayılımının ve plazma hızının AC frekansına göre değişimini incelemiştir. Düşük sürüm frekanslarında plazma yayılımındaki değişimi ortaya koymuştur ancak yüksek değerlerde bu yayılımın sürüm frekansına bağlı olmadığını belirtmiştir. Bunun aksine, frekans arttırıldığında plazmanın hızında da artış olduğu çalışmasında görülmektedir (Orlov, 2006). Kotsonis ve diğ. (2014) yaptıkları çalışmada plazma aktüatörleri kanadın arka kısmına yerleştirip kanat etrafındaki akışın kontrolü üzerine çalışmışlardır. Plazma aktüatörün kanadın arka kısmına yakın iz bölgesindeki yapıyı değiştirdiğini buna bağlı olarak dominant girdap kopma frekansının azaltıldı̆̆ını ortaya koymuşlardır. Farklı Reynolds sayılarında yapılan bu çalışmada, hücum açısının 0 ve 5 derece olduğu değerlerde kaldırma katsayısının incelemesini de uygulama voltajı ve sürüm frekansı açısından incelemişlerdir.

Uygulama voltajı artışının kaldırma katsayısı üzerine yaptığı iyileştirmede sürüm frekansına kıyasla daha etkili olduğunu ortaya koymuşlardır (Kotsonis ve diğ., 2014). Güler ve diğ. (2018) yaptıkları çalışmada NACA 0015 uçak kanadı etrafındaki akışın kontrolünde kullandıkları plazma aktüatörlerini farklı tip sinyalle sürmüşlerdir. Hücum açısının 10 derece olduğu değerde, sinyal modülasyonu ve sürüm frekansının uygun seçilmesi ile kaldırma katsayısı üzerinde iyileştirme sağlamakla birlikte enerji tasarrufunun da mümkün olduğunu deneysel çalışmalarında ortaya koymuşlardır (Güler ve diğ., 2018).

Taleghani ve diğ. (2012) NFL 0414 tipi kanat profiline uyguladıkları plazma aktüatörleri üç farklı konumda kullanmışlardır. Uygulama voltajının $14 \mathrm{kV}$ ve sürüm frekansının $28 \mathrm{kHz}$ olduğu değerler için yapılan çalışmada post stol açılarında incelemede bulunmuşlardır. Yaptıkları çalışmanın sonuçlarında sürüm frekansının artışının plazmanın hızını arttırdığını göstermişlerdir. Ayrıca, düşük sürüm frekanslardaki düşük duty cycle'lar ile daha iyi kaldırma katsayısı elde edildiğini ortaya koymuşlardır (Taleghani ve diğ., 2012). Sürüm frekansının duty cycle'ı üzerine inceleme yapılan diğer bir çalışma ise Sun ve diğ. (2015) tarafından $10 \mathrm{kHz}$ değerinde farklı voltajlar için yapılmıştır. Bu çalışmada, 0.1 ile 1 aralığındaki belirli değerlerde duty cyle uygulaması hücum açısı 17 ve 20,5 derece için NACA0015 kanat profilinde için sonuçlar ortaya konulmuştur. Kanadın kaldırma katsayısının iyileştirmesinin en iyi 0,25 duty cycle değerinde olduğunu $12 \mathrm{~m} / \mathrm{s}$ ile $75 \mathrm{~m} / \mathrm{s}$ akış hızı için olduğunu göstermişlerdir (Sun ve diğ., 2016). Han ve diğ. (2015) yaptıkları çalışmada nanosecond pulsed DBD plazma aktüatörlerinin $0.2 \mathrm{kHz}$ ile $1.8 \mathrm{kHz}$ aralığında sürüm frekansı uygulanması ile kaldırma kuvvetinin arttırılabileceğini ve 
sürükleme kuvvetinin azaltılabileceğini belirtmişlerdir. Sürüm frekansının azaltılması ile kaldırma kuvvetinde daha iyi etki elde etmişlerdir. Ayrıca çalışmalarında buldukları sonuçlar ile düşük hücum açılarında kalkış sağlayan hava araçlarının kalkış anında ilave iyileştirme elde edeceğini ve tırmanma performansının arttırılacağını belirtmişlerdir (Han ve diğ., 2015). Farklı elektrot geometrileri ve farklı sürüm frekansı üzerine nanosecond pulsed DBD plazma aktüatörlerin kullanıldığı başka bir çalışmada ise akış kontrol etkilerinin sürüm frekansına bağlı olduğu bulunmuştur (Zhao ve diğ., 2015). Yine aynı çalışmada, düşük frekansta swept tipi kanat profilinin aerodinamik performansındaki iyileşmenin daha iyi olduğunu belirtmişlerdir.

Literatürdeki çalışmalar göz önüne alındığında çalışmaların büyük çoğunluğu stol açısı ve post stol açıları için incelenmiştir. Ayrıca, uygulama ve sürüm frekansı etkilerinin kaldırma katsayısı üzerine etkileri belirli hücum açılarında ortaya konulmuştur. Bu deneysel çalışmada, hücum açısı aralığı açısından frekansın ve voltajın etkileri daha sık aralıkta incelenmektedir. İlave olarak, sürüm frekansı ve uygulama voltajı için ise her hücum açısında değerlendirmeler yapılmıştır.

\section{MATERYAL VE METOT (MATERIAL AND METHOD)}

\section{Rüzgâr Tüneli ve NACA0015 Uçak Kanadı (Wind Tunnel and NACA0015 Airfoil)}

NACA0015 uçak kanadının etrafındaki akış kontrolü üzerine yapılan deneyler emmeli tip-açık çevrim rüzgâr tünelinde Reynolds sayısı 48000 değerinde yapılmıştır. Rüzgâr tünelinin daralma oranı 6.3:1'dir. Deneylerin yapıldığı bu tünel $57 \mathrm{~cm} \times 57 \mathrm{~cm}$ kare kesitli ve $100 \mathrm{~cm}$ uzunluğu olan test bölgesine sahiptir. Kanat modeli test bölgesine kuvvet ölçümleri için dikey akış görselleştirmesi için Şekil 1'deki gibi yatay yönde yerleştirilmiştir. Türbülans şiddeti \%1'in altındadır. Kanat modeli PLA malzemesinden 3D yazıcı teknolojisi ile üretilmiştir. Kanat modelinin veter uzunluğu $150 \mathrm{~mm}$ olup kanat açıklı̆̆ ise $540 \mathrm{~mm}$ 'dir. Uç etkileri ortadan kaldırmak için iki adet $280 \mathrm{~mm}$ çapa sahip uç plaka kanat kenarlarına yerleştirilmiştir.
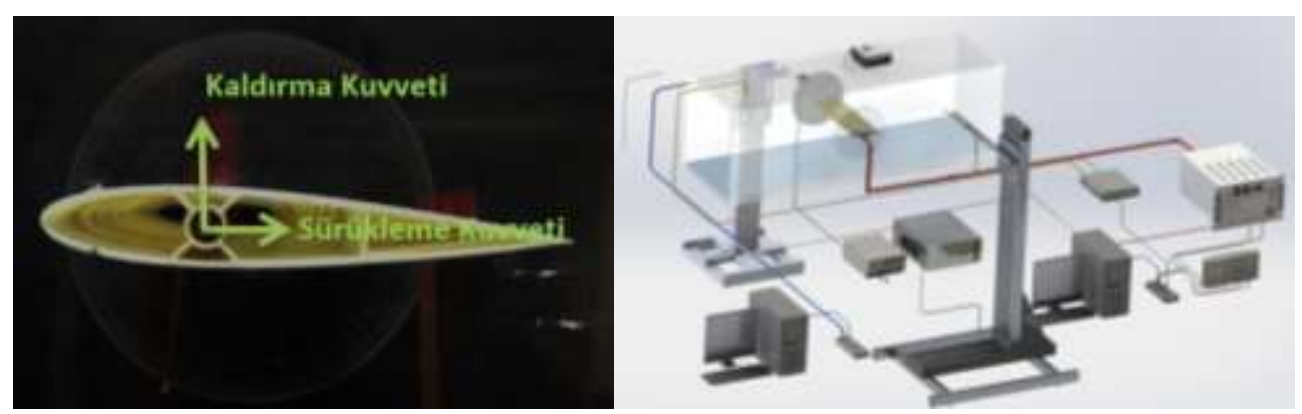

Şekil 1. D NACA0015 kanat modeli ve deneysel kurulum

Figure 1. NACA0015 airfoil model and experimental setup of the study

\section{Plazma Üretimi ve Plazma Aktüatör Yapısı (Plasma Generation and the Structure of Plasma Actuator)}

Deneylerde kullanılan plazma aktüatör yapısı Şekil 2'de görüldüğü gibi iki bakır elektrottan ve bir di-elektrik malzemeden oluşmaktadır. Hava ile temas eden elektrota yüksek voltaj uygulanırken gömülü elektrot topraklanmaktadır. Bu elektrotlar arasına di-elektrik malzeme yerleştirilmiştir. Dielektrik malzeme olarak Kapton seçilmiştir. Bu elektrotların genişliği 5 mm olup kalınlığı 0.05 mm'dir. Elektrot kalınlığı çok düşük olması nedeniyle model yüzey geometrisini değiştirmediği literatürdeki kaynaklardan bilinmektedir. Plazma aktüatörler kanat modelinin "leading edge" yani $\mathrm{x} / \mathrm{C}=0.1$ konumuna yerleştirilmişlerdir.

Elektrotların köşelerinde yüksek elektrik konsantrasyonu oluşmaktadır ve buna bağlı olarak bu durumun elektrotların yanmalarına sebebiyet verdiği gözlemlenmiştir. Bu problemin önüne geçebilmek adına elektrotların köşeleri 1mm çapında yuvarlatılmıştır. Plazma aktüatörler yüksek voltaj amfisi ile 
çalıştırılmıştır. Bu çalışmada, uygulama voltajı 5 ile $7 \mathrm{kV}$ aralığında $1 \mathrm{kV}$ arttırılarak, sürüm frekansı ise 2.5 ile $5.5 \mathrm{kHz}$ aralığında $1 \mathrm{kHz}$ arttırılarak deneyler gerçekleştirilmiştir. Tektronix marka P6015 model yüksek voltaj probu yardımıyla elektriksel özellikler tespit edilmiştir. Sinyal özellikleri ise Fluke marka 80i-110s model akım probu yardımıyla gözlemlenmiştir. Yüksek voltaj probu ve akım probu TT-technic marka TDS2012B model osiloskoba bağlanmıştır.

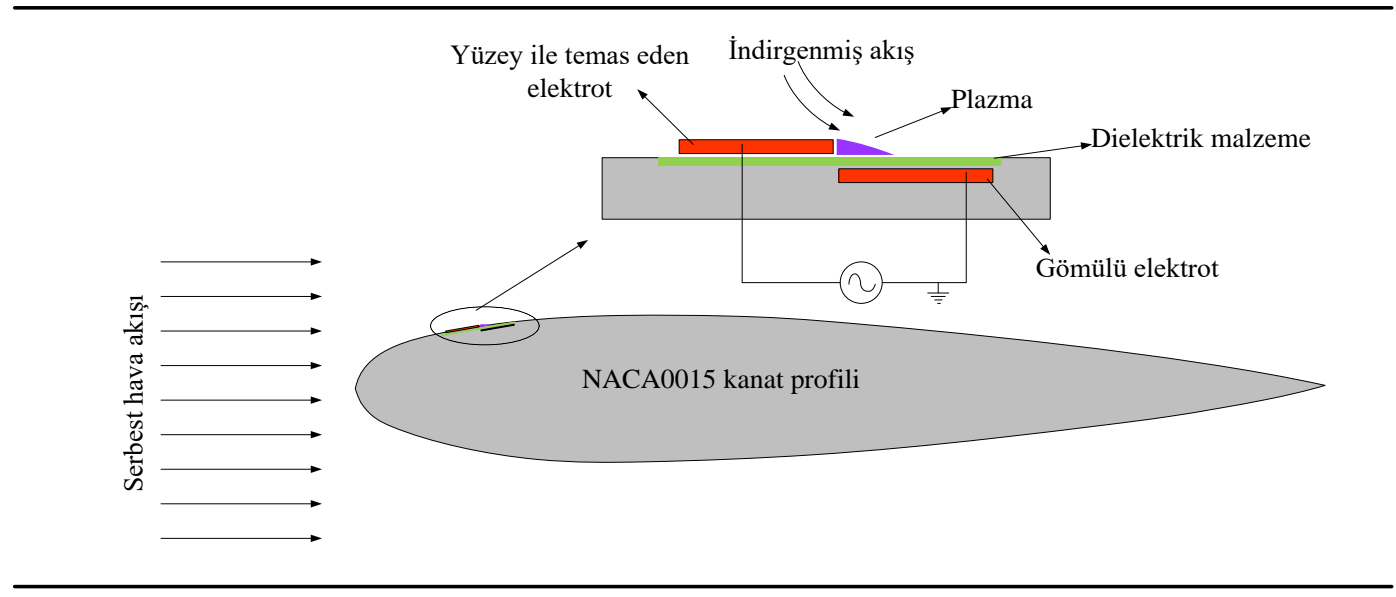

Şekil 2. Plazma aktüatör yapısı ve kanat üzerindeki konumu

Figure 2. The structure of a plasma actuator and position on the airfoil

\section{Aerodinamik Kuvvet Ölçüm Sistemi (Aerodynamic Force Measurement System)}

Model üzerine etki eden kaldırma kuvvetini ölçebilmek için Şekil 3'de görülen ATI model 6 eksenli yük hücresi kullanılmıştır. Bu yük hücresi bilgisayar kontrollü döndürme aparatı ile entegre hale getirilip farklı hücum açılarında kuvvet değerlerinin ölçülmesinde kullanılmıştır. Ölçümler $1 \mathrm{kHz}$ örnekleme frekansında 10 sn boyunca her bir değer için gerçekleştirilmiştir. Toplamda 5000 veri, veri toplama kartı yardımıyla alınmıştır. Her bir deney 3 kez tekrar edilmiştir ve ortalaması hesaplanmışır. Bunun nedeni, deneylerin tekrarlana bilirliğini ortaya koymak ve hata oranını en aza indirebilmektedir. Belirsizlik analizi neticesinde kuvvet ölçüm sisteminin hata payının \%5'den az olduğu bulunmuştur. Belirsizlik analizinin hesaplanmasında yük hücresi değerleri, hücum açısının ayarlanmasında yapılabilecek ölçüm hatası ve model geometrisi üretiminde model uzunluklarında meydana gelebilecek hatalar göz önüne alınmıştır.

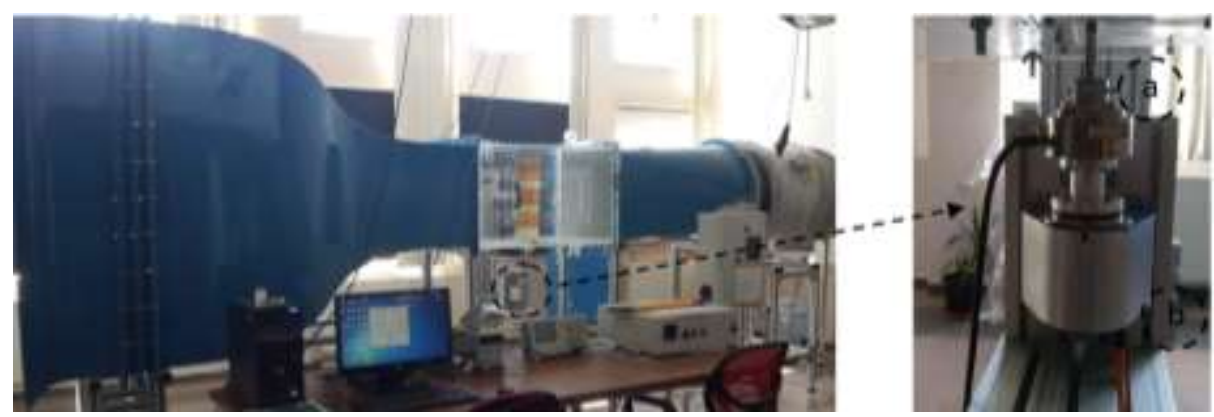

Şekil 3. Rüzgâr tüneli test bölgesine bağlı kuvvet ölçüm sistemi (a) ve döndürme aparatı (b) Figure 3. Load cell system placed in wind tunnel test section (a) and rotary unit (b).

\section{BULGULAR VE TARTIŞMALAR (RESULTS AND DISCUSSIONS)}

Aşağıda Şekil 4'te NACA0015'e ait kaldırma katsayısının hücum açısı ile değişimi verilmiştir. Yapılan deneyde, 3.5 kHz'de 7 kV'da maksimum kaldırma elde edilmiştir. Aynı zamanda stol'a girme 
durumu da geciktirilmiştir. Bu durum özellikle $5 \mathrm{kV}$ da daha belirgin haldedir. Ancak sürüm frekansı $3.5 \mathrm{kHz}$ değerinden $4.5 \mathrm{kHz}$ değerine arttırıldığında $7 \mathrm{kV}$ da 4 derece stol açısı daha da ötelenmiştir. Aynı durumda 5 kV'da bu kez 2 derece öteleme elde edilmiştir. Bunların yanı sıra, 6 kV'da maksimum kaldırma kuvveti azalmış olsa da stol sonrası açıda uçak kanadı stola girmeyerek kaldırma kuvveti katsayısı 0.45 seviyelerinde seyretmiştir. Uçak kanadının emme yüzeyinde düşük Re sayılarında oluşan "laminer seperation bubble" oluşumunun plazmanın etkisi ile bir miktar bozulmasından kaynaklı 6 kV'daki kaldırma kuvveti katsayısı eğrisi daha yatay seyretmiş görünmektedir.
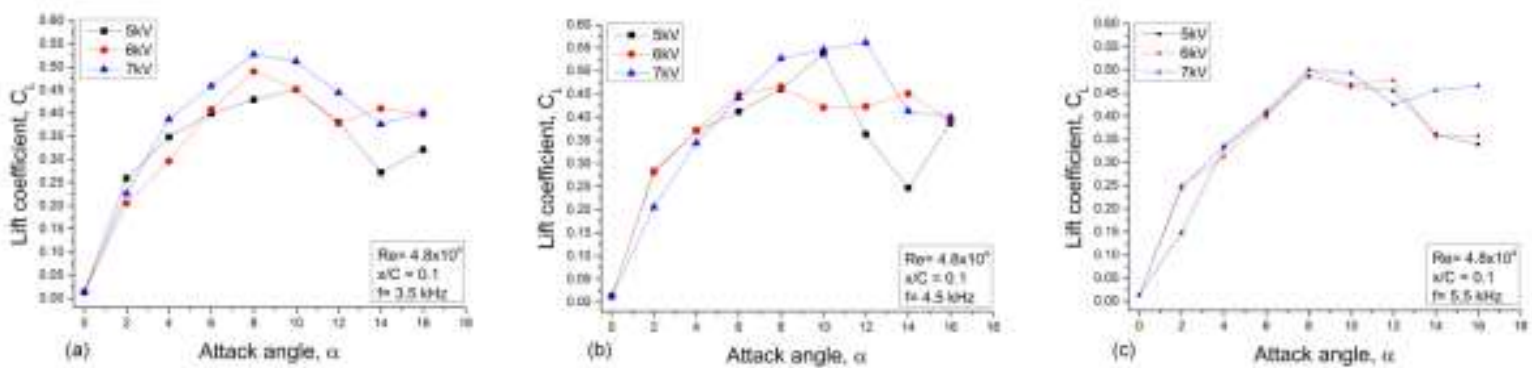

Şekil 4. NACA0015 kanat profiline uygulanan sürüm frekansı değişimi ve bu durumun kaldırma katsayısına etkisi, a) $3.5 \mathrm{kHz}$, b) $4.5 \mathrm{kHz}$, c) $5.5 \mathrm{kHz}$

Figure 4. Variation excitation frequency applied to NACA0015 airfoil and its effect on lift coefficient, a) $3.5 \mathrm{kHz}, \mathrm{b}) 4.5 \mathrm{kHz}$, c) $5.5 \mathrm{kHz}$

Aşağıda Şekil 5'te bu kez NACA0015 kanat profiline uygulanan sürüm voltaj değişimi ve bu durumun kaldırma katsayısına etkisi verilmiştir. Grafiklerden de görüldüğü üzere, $4.5 \mathrm{kHz}$ plazma sürüm frekansında tüm stol öncesi açılarda sürüm voltajları için en iyi performansı göstermiştir. Diğer taraftan, 7 kV'da ise $4.5 \mathrm{kHz}$ hem stol açısının ötelenmesinde etkili olmuştur. Aynı zamanda bu şartlarda yapılan deneylerde elde edilen en yüksek kaldırma kuvveti katsayısı değerine ulaşılmıştır.
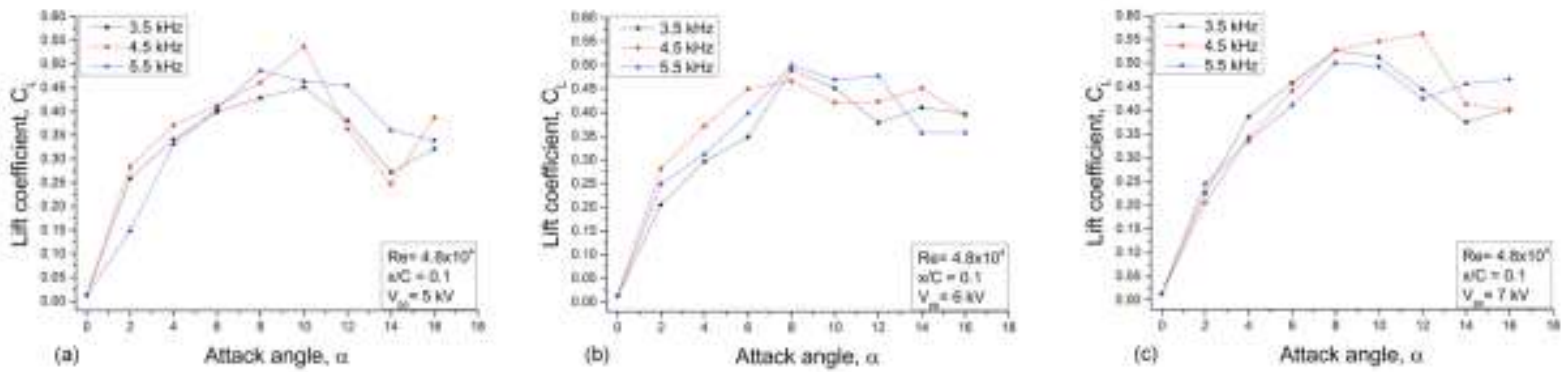

Şekil 5. NACA0015 kanat profiline uygulanan voltaj değişimi ve bu durumun kaldırma katsayısına etkisi, a) $5 \mathrm{kV}$, b) $6 \mathrm{kV}$, c) $7 \mathrm{kV}$

Figure 5. Variation excitation frequency applied to NACA0015 airfoil and its effect on lift coefficient, a) $5 \mathrm{kV}$, b) $6 \mathrm{kV}$, c) $7 \mathrm{kV}$

Yapılan uygulamalarda görülen diğer bir durum ise plazma aktüatörlerinin sürülmesinde kullanılan voltajın artması ile kanadın etrafındaki akış üzerindeki etkinliği de lineer olmayan bir yapıda olsa da artmaktadır. Ancak aynı durum incelendiğinde, plazma sürüm frekansı değişiminin kaldırma kuvveti üzerinde iyileştirici etkisi doğrudan bir ilişki şeklinde olmayıp daha çok spesifik değerlerde belirginleşen bir iyileştirme şeklinde görünmektedir.

Aşağıda Şekil 5 'te kaldırma kuvveti katsayısının plazma sürüm frekansına göre değişimi verilmiştir. Grafiklerden de görüleceği üzere yapılan inceleme her bir hücum açısı değeri için farklı voltaj ve frekanslar için incelenmiştir ve sonuçları grafikler halinde aşağıda sunulmuştur. Şekil 6-a'da plazma sürüm frekansı $2.5 \mathrm{kHz}$ ile $5.5 \mathrm{kHz}$ arasında değiştirilmiştir. Bu aralıkta, plazma sürüm voltajı da $5 \mathrm{kV}, 6$ $\mathrm{kV}$ ve $7 \mathrm{kV}$ değerlerinde olmak üzere deneyler yapılmıştır. Elde edilen sonuçlar değerlendirildiğinde belirli bir plazma sürüm voltaj değeri için arttırılan plazma sürüm frekansının kaldırma kuvveti 
katsayısı üzerinde birebir oransal bir artış sağlamadığı görülmektedir. Bu nedenle de plazma sürüm frekansının arttırılması kaldırma kuvveti katsayısında artış sağlamamaktadır. Diğer bir önemli bulgu ise farklı voltaj değerlerinin farklı frekanslarda daha etkin hale geldiğinin görülmesidir. Bu kapsamda yapılan değerlendirme maksimum kaldırma kuvveti katsayısı durumu $4.5 \mathrm{kHz}$ frekans değerinde $5 \mathrm{kV}$ ve $6 \mathrm{kV}$ voltaj değerlerinde elde edilmiş görünmektedir. Aynı şekilde durum B'de (Şekil 6-b) ise 4 derece hücum açısı için aynı inceleme tekrarlanmıştır. Bu durumda ise maksimum kaldırma kuvveti katsayısı $3.5 \mathrm{kHz}$ frekans değerinde $7 \mathrm{kV}$ voltaj değerinde elde edilmiş görünmektedir. Aynı şekilde durum C'de (Şekil 6-c) ise 6 derece hücum açısı için aynı inceleme tekrarlanmıştır. Bu durumda ise maksimum kaldırma kuvveti katsayısı $4.5 \mathrm{kHz}$ frekans değerinde $6 \mathrm{kV}$ ve $7 \mathrm{kV}$ voltaj değerlerinde elde edilmiş görünmektedir. Aynı şekilde durum D'de (Şekil 6-d) ise 8 derece hücum açısı için aynı inceleme tekrarlanmıştır. Bu durumda ise maksimum kaldırma kuvveti katsayısı $3.5 \mathrm{kHz}$ ve $4.5 \mathrm{kHz}$ frekans değerlerinde $7 \mathrm{kV}$ voltaj değerinde elde edilmiş görünmektedir. Aynı şekilde durum E'de (Şekil 6-e) ise 10 derece hücum açısı için aynı inceleme tekrarlanmıştır. Bu durumda ise maksimum kaldırma kuvveti katsayısı $4.5 \mathrm{kHz}$ frekans değerinde $7 \mathrm{kV}$ voltaj değerinde elde edilmiş görünmektedir. Ayrıca, $7 \mathrm{kV}$ plazma sürüm voltajının genel olarak diğer tüm frekanslarda da baskın olduğu ve en iyi kaldırma kuvveti katsayısının elde edildiği görülmektedir. Aynı şekilde durum F'de (Şekil 6-f) ise 12 derece hücum açısı için aynı inceleme tekrarlanmıştır. Bu durumda ise maksimum kaldırma kuvveti katsayısı $4.5 \mathrm{kHz}$ frekans değerinde $7 \mathrm{kV}$ voltaj değerinde elde edilmiş görünmektedir. Ayrıca, $7 \mathrm{kV}$ plazma sürüm voltajının genel olarak diğer tüm frekanslarda da baskın olduğu ve en iyi kaldırma kuvveti katsayısının elde edildiği görülmektedir.
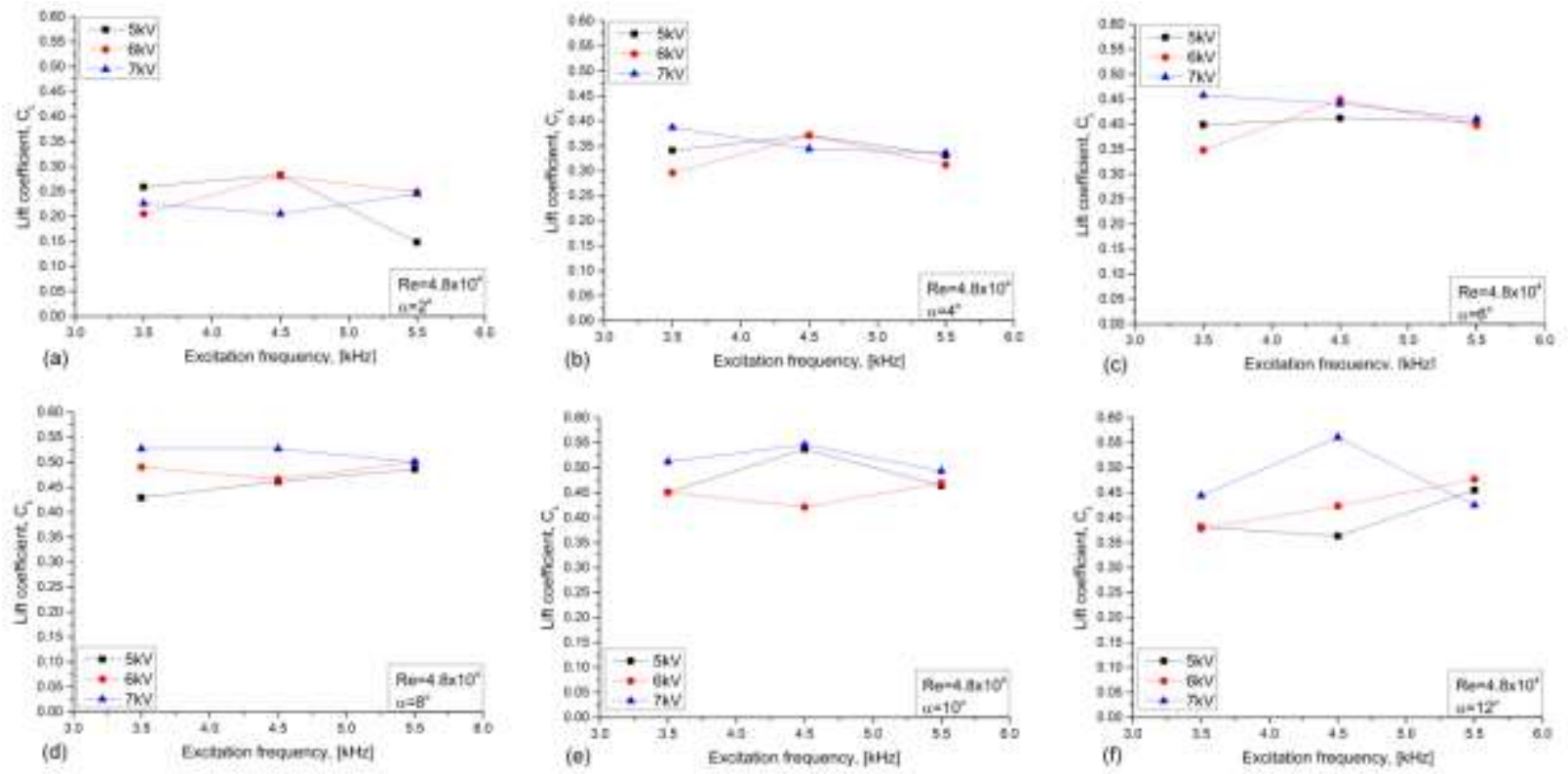

Şekil 6. NACA0015 kanat profiline uygulanan sürüm voltaj-frekans değişimi ve bu durumun kaldırma katsayısına etkisi

Figure 6. Variation of excitation frequency-applied voltage for NACA0015 airfoil and its effect on lift coefficient

\section{SONUÇ (CONCLUSION)}

Yapılan deneysel çalışmalar ile NACA0015 kanat modeli için elde edilen deney sonuçları da dikkate alınarak plazma sürüm voltajı ve frekansının kanadın kaldırma kuvveti katsayısı üzerine etkisi Reynolds sayısı 48000 değerinde olmak üzere incelenmiştir. Elde edilen sonuçlardan da görüldügü üzere plazma sürüm voltajının kanadın kaldırma kuvveti katsayısı üzerine etkisi yaklaşık olarak doğrusal olarak değerlendirilebilecek iken plazma sürüm frekansının kanadın kaldırma kuvveti katsayısı üzerine etkisi doğrusal görünmemektedir. Bu nedenle de kanadın kaldırma kuvveti katsayısının arttırılması için plazma sürüm voltajının arttırılması bir çözüm iken plazma sürüm frekansının arttırılması ya da 
azaltılması her bir kanat açısı ve uygulama voltajı için ayrıca değerlendirme gerektirmektedir. Bunun nedeni ise söz konusu ilişkinin doğrusal olmayan yapıda olması ve yukarıda değerlendirmelerden de görüldügü üzere genelleştirilebilecek net bir sonuç vermemesidir. Bu kapsamda yapilacak çalışmalar için deneylerin daha sık aralıklarla incelenecek hücum açısı için tekrarlanması ve durumun daha net hale getirilmesi önerilmektedir. Ancak, bu deneyler çok uzun süren yoğun bir çalışmayı gerektirecektir. $\mathrm{Bu}$ durumda da sonucun, yapılan çalı̧̧ma ile benzer nitelikte doğrusal olmayan bir bağıntıyı ortaya koyması beklenmektedir. Ancak bu durumda farklılık olarak, oluşturulacak daha temel bir yapı kullanılarak bu doğrusal olmayan yapının değişimi daha anlaşılır hale getirilip bu kapsamda yapılacak kontrol uygulamalarında kullanılabilir. Ortaya çıkan sonuçlar itibarı ile kanadın kaldırma kuvveti katsayısının arttırılması için en uygun yöntem uygulanan plazma sürüm voltajının arttırılması olarak görülmektedir. Ancak, bu durumda sistemi sürmek için ihtiyaç duyulacak enerji miktarında da artış olacağı dikkate alınmalıdır.

\section{SEMBOLLER (SYMBOLS)}
$\alpha \quad$ : Hücum açısı
C : Veter uzunluğu
$C_{L}:$ Kaldırma kuvveti katsayısı
f : Plazma sürüm frekansı
Re : Reynolds sayıs
$x \quad$ : Eksen

\section{KAYNAKLAR (REFERENCES)}

Corke, T. C., Enloe, C. L., Wilkinson, S. P., 2010, “Dielectric barrier discharge plasma actuators for flow control", Annual Review of Fluid Mechanics, Vol. 42, pp.505-529.

Debien, A., Benard, N., Moreau, E., 2012, "Streamer inhibition for improving force and electric wind produced by DBD actuators", Journal of Physics D: Applied Physics, Vol. 45, No. 215201, pp. 113.

Güler, A. A., Seyhan, M., Akansu, Y. E., 2018, “Effect of signal modulation of DBD plasma actuator on flow control around NACA 0015", Journal of Thermal Science and Technology, Vol. 38, pp.85105.

Han, M., Li, J., Niu, Z., Liang, H., Zhao, G., Hua, W., 2015, “Aerodynamic performance enhancement of a flying wing using nanosecond pulsed DBD plasma actuator", Chinese Journal of Aeronautics, Vol.28, pp.377-384.

Kotsonis, M., Pul, R., Veldhuis, L., 2014, "Influence of circulation on a rounded-trailing-edge airfoil using plasma actuators", Experiments in Fluids, Vol. 55, No. 1772, pp. 1-14.

Orlov, D. M., 2006, "Modelling and simulation of single dielectric barrier discharge plasma actuators", PhD Thesis, University of Notre Dame.

Sun, M., Yang, B., Peng, T., Lei, M., 2016, “Optimum duty cycle of unsteady plasma aerodynamic actuation for NACA0015 airfoil stall seperation control", Plasma Science and Technology, Vol. 18, pp.680-685.

Taleghani, A. S., Shadaram, A., Mirzaei, M., 2012, “Effects of duty cycles of the plasma actuators on improvement of pressure distribution above a NFL0414 airfoil", IEEE Transaction on Plasma Science, Vol. 40, pp.1434-1440.

Zhao, G., Li, Y., Liang, H., Han, M., Wu, Y., 2015, "Flow seperation control on swept wing with nanosecond pulse driven DBD plasma actuators", Chinese Journal of Aeronautics, Vol. 28, pp.368-376. 